\title{
5-Hydroxytryptamine metabolism
}

\section{in rat brain and liver homogenates}

\author{
A. FELDSTEIN AND O. WILLIAMSON
}

Worcester Foundation for Experimental Biology, Shrewsbury, Massachusetts 01545, U.S.A.

1. The metabolism of 5-hydroxyindoleacetaldehyde derived from 5-hydroxytryptamine incubated with tissue homogenates was studied as an indicator of aldehyde dehydrogenase and alcohol dehydrogenase activities.

2. In liver and brain from rats, there were indications of the presence of one or more aldehyde dehydrogenases which were stimulated by $\mathrm{NAD}^{+}$to a greater extent than by NADP+.

3. In liver from rats, there were indications of the presence of one or more alcohol dehydrogenases, which were stimulated by NADH to a greater extent than by NADPH.

4. In brain from rats, there were indications of the presence of one or more alcohol dehydrogenases which were stimulated by NADPH to a greater extent than by NADH.

Eccleston, Moir, Reading \& Ritchie (1966) reported that 5-hydroxytryptamine (5-HT) was converted to 5-hydroxytryptophol by way of 5-hydroxyindoleacetaldehyde in rat and human brain homogenates. These investigators found that the conversion in brain was effected by an alcohol dehydrogenase which depended on NADPH (Eccleston, Moir, Reading \& Ritchie, 1966) rather than NADH as in liver (Kveder, Iskric \& Keglevic, 1962 ; Feldstein \& Wong, 1965a, b). It was reported also that the conversion of 5-HT to 5-hydroxyindoleacetic acid (5-HIAA) by way of 5-hydroxyindoleacetaldehyde in rat brain homogenates was more effective in the presence of NADP + than NAD ${ }^{+}$(Eccleston, Moir, Reading \& Ritchie, 1966), although another investigator (Deitrich, 1966) found that $\mathrm{NAD}^{+}$was the more effective. The effects of the coenzymes on 5-HT metabolism in both rat liver and brain homogenates were re-investigated and the results reported herein.

\section{Methods}

Male rats, Sprague-Dawley descendants, 150-165 g, were obtained from Charles River Laboratories. A $2 \%$ brain or $0.5 \%$ liver homogenate was prepared in $0.25 \mathrm{M}$-sucrose, with cooling. For each tissue sample, five incubation flasks were set up, control and one flask for each of the four coenzymes: $\mathrm{NAD}^{+}, \mathrm{NADP}^{+}$, NADH and NADPH. The final incubation mixture contained $10 \mu \mathrm{g}$ of 5-hydroxytryptamine $-{ }^{14} \mathrm{C}$ creatinine sulphate hydrate, $1 \%$ brain or $0.25 \%$ liver, $1 \mathrm{mg}$ of coenzyme, $0.125 \mathrm{M}$-sucrose and $0.25 \mathrm{M}$-phosphate buffer, $\mathrm{pH} 7.4$, in a total volume of 
$1 \mathrm{ml}$. and the incubation was carried out for $80 \mathrm{~min}$ at $37^{\circ} \mathrm{C}$ with shaking in air. The $5-\mathrm{HT}-{ }^{14} \mathrm{C}$ salt (specific activity, $98 \mu \mathrm{c} / \mathrm{mg}$ ) was obtained from Nuclear-Chicago, Inc. The coenzymes used, except where noted, were obtained from Sigma Chemical Co. The analysis of metabolites was by the previously described method (Feldstein \& Wong, 1965a, b), which combines solvent extraction procedures with paper chromatographic separation of 5-hydroxytryptophol and 5-hydroxyindoleacetaldehyde.

\section{Results}

The incubation of a $0.25 \%$ liver homogenate (Table 1) with 5-HT for $80 \mathrm{~min}$ under the conditions described indicated that about $68 \%$ of the 5-HT was metabolized by monoamine oxidase (MAO) to 5-hydroxyindoleacetaldehyde with subsequent formation of 5-hydroxytryptophol and 5-HIAA. Approximately the same percentage of $5-\mathrm{HT}-62 \%$-was metabolized by $1 \%$ brain homogenate (Table 2 ). Liver MAO therefore was about 4 times more active than brain MAO. In a series of $10 \mathrm{~min}$ incubations, where product formation was linear with respect to time, liver MAO (six rats) was again 4 times more active than brain MAO (six rats).

In liver incubation mixtures, 5-HIAA formation occurred in the absence of exogenous coenzymes (Table 1), which indicated aldehyde dehydrogenase activity. If

TABLE 1. Metabolism of 5-hydroxytryptamine in rat liver homogenates

Mean percentage (range observed in five rats) of 5-HT metabolized

5-HT

metabolites

Total products formed

5-Hydroxyindole-

acetaldehyde

5-Hydroxytryptophol

5-HIAA

$\begin{array}{ccc}\text { Control } & \text { NAD } & \text { NADP } \\ 68 & 71 & 71 \\ (60-78) & (61-84) & (57-83) \\ 33 & 1 & 12 \\ (16-48) & (0-1) & (1-21) \\ 6 & 2 & 5 \\ (4-10) & (0-4) & (3-10) \\ 24 & 67 & 50 \\ (7-46) & (55-83) & (28-75)\end{array}$

$\begin{array}{cc}\text { NADH } & \text { NADPH } \\ 65 & 60 \\ (55-81) & (42-79) \\ 6 & 18 \\ (5-8) & (4-31) \\ 36 & 11 \\ (22-47) & (4-29) \\ 15 & 27 \\ (7-26) & (7-60)\end{array}$

The final incubation mixture contained (per ml.): $10 \mu \mathrm{g}$ of 5-HT creatinine sulphate hydrate; $0.25 \%$ liver homogenate; $0.125 \mathrm{M}$-sucrose; $0.25 \mathrm{M}$-phosphate buffer at pH $7.4 ; 1 \mathrm{mg}$ of coenzyme.

TABLE 2. Metabolism of 5-hydroxytryptamine in rat brain homogenates Mean percentage (range of five rats) of 5-HT metabolized in $80 \mathrm{~min}$

$\begin{array}{lccccc}\begin{array}{c}\text { 5-HT } \\ \text { metabolites }\end{array} & \text { Control } & \text { NAD } & \text { NADP+ } & \text { NADH } & \text { NADPH } \\ \text { Total products formed } & 62 & 59 & 54 & 54 & 55 \\ & (48-73) & (45-80) & (39-73) & (38-73) & (38-80) \\ \text { 5-Hydroxyindole- } & 38 & 21 & 30 & 28 & 24 \\ \text { acetaldehyde } & (23-49) & (11-29) & (22-42) & (15-38) & (16-27) \\ \text { 5-Hydroxytryptophol } & 3 & 2 & 3 & 4 & 13 \\ \text { 5-HIAA } & (3-3) & (2-3) & (2-5) & (3-5) & (8-21) \\ & 13 & 29 & 14 & 16 & 11 \\ & (12-15) & (21-39) & (10-18) & (13-23) & (8-16)\end{array}$

The final incubation mixture contained (per ml.): $10 \mu \mathrm{g}$ of 5-hydroxytryptamine creatinine sulphate hydrate; $1 \%$ brain homogenate; $0.125 \mathrm{M}$-sucrose; $0.25 \mathrm{M}$-phosphate buffer at $\mathrm{pH} 7.4 ; 1 \mathrm{mg}$ of coenzyme. 
the homogenate was prepared at room temperature or preincubated at $37^{\circ} \mathrm{C}$ for $15 \mathrm{~min}$, instead of being prepared with cooling and used directly, total product formation (hence MAO activity) was not altered but 5-HIAA formation was reduced; exogenous $\mathrm{NAD}^{+}$reactivated the aldehyde dehydrogenase under theso conditions. The addition of $\mathrm{NAD}^{+}$to the incubation mixture prepared from the cooled homogenates (Table 1) also greatly increased 5-HIAA formation ; NADP+ caused a moderate increase. The source of the $\mathrm{NAD}^{+}$determined in part the rate of 5-HIAA formation (Table 3). 5-Hydroxytryptophol formation was low in the absence of exogenous coenzymes (control values, Table 1). NADH moderately increased 5-hydroxytryptophol formation (Table 1) ; whereas, NADPH caused only a slight increase $(P<0.05)$.

In rat brain incubation mixtures (Table 2) the formation of 5-HIAA was moderately increased by the addition of $\mathrm{NAD}^{+}$. If an adjustment for the difference in total product formation is made, a small increase $(P<0.05)$ with NADP + in the relative amount of 5-HIAA formed is evident (Tables 2 and 4). Formation of 5-hydroxytryptophol was slightly but not significantly increased by NADH, and moderately increased $(P<0.05)$ by NADPH (Table 2$)$. NADP ${ }^{+}$partially prevented the NADPH-induced increase in 5-hydroxytryptophol formation, and there was a simultaneous increase in 5-HIAA formation (Table 4).

\section{Discussion}

The formation of 5-HIAA from 5-hydroxyindoleacetaldehyde derived from 5-HT in guinea-pig (Weissbach, Redfield \& Udenfriend, 1957), rat (Table 1; Deitrich, 1966) and human (Feldstein, Williamson \& Tedeschi, unpublished) liver incubations

TABLE 3. Conversion of 5-hydroxytryptamine to 5-HIAA in rat liver homogenates as a function of $N A D+$ source

Mean percentage (range) of 5-hydroxytryptamine converted to 5-hydroxyindoleacetaldehyde and

Source of NAD +

Control

Company A

Company B

Company C-Lot 1

Company C-Lot 2

$$
\text { 5-HIAA }
$$

$7 \cdot 9(7 \cdot 5-8 \cdot 3)$

$6 \cdot 9(6 \cdot 6-7 \cdot 2)$

$7 \cdot 2(6 \cdot 8-7 \cdot 6)$

$6 \cdot 9(6 \cdot 4-7 \cdot 3)$

$7 \cdot 1(6 \cdot 9-7 \cdot 5)$

$$
\begin{aligned}
& \text { 5-HIAA formed } \\
& \text { expressed as the } \\
& \text { mean percentage } \\
& \text { (range) of the total } \\
& \text { products formed } \\
& 8(6-8) \\
& 29(25-34) \\
& 47(41-54) \\
& 57(48-66) \\
& 68(63-73)
\end{aligned}
$$

The final incubation mixture contained (per $\mathrm{ml}$.): $10 \mu \mathrm{g}$ of 5-hydroxytryptamine creatinine sulphate hydrate; $0.25 \%$ of liver homogenate; $0.125 \mathrm{M}$-sucrose; $0.25 \mathrm{M}$-phosphate buffer at pH $7.4 ; 1 \mathrm{mg}$ of NAD+. Incubation time was $5 \mathrm{~min}$ and product formation was linear with respect to time.

TABLE 4. 5-Hydroxytryptamine metabolism in rat brain homogenates as a function of NADPH and varying concentrations of $N A D P+$

Relative percentage of products formed in $80 \mathrm{~min}$

5-Hydroxytryptamine metabolites

5-Hydroxyindoleacetaldehyde

5-Hydroxytryptophol

5-HIAA $\mathrm{mg}$ of $\mathrm{NADP}+/ \mathrm{ml}$.

in the presence of

$1 \mathrm{mg}$ of NADPH $/ \mathrm{ml}$. incubation mixture

$\begin{array}{rrrr}0 & 0 \cdot 5 & 1 \cdot 0 & 2 \cdot 0 \\ 52 & 50 & 53 & 55 \\ 21 & 16 & 12 & 9 \\ 27 & 34 & 35 & 36\end{array}$


was stimulated to a greater extent by $\mathrm{NAD}^{+}$than by $\mathrm{NADP}^{+}$. These results suggest that there may be two aldehyde dehydrogenases in liver, a NAD+-linked and a NADP+-linked enzyme. There is a precedent for the separation of two enzymes which yield the same product, the NAD+- and NADP+-linked isocitrate dehydrogenase (Plaut \& Aogaichi, 1967). Stimulation of 5-HIAA formation may be due, however, to a single enzyme which functions with both $\mathrm{NAD}^{+}$and NADP+ or which functions with $\mathrm{NAD}^{+}$derived by rapid dephosphorylation of NADP ${ }^{+}$ (Sanadi, 1952 ; Stollar \& Kaplan, 1961 ; Jouany, 1965).

We have also found that NADH stimulated 5-hydroxytryptophol formation in rat (Feldstein \& Wong, 1965a, b; Table 1) and human (Feldstein, Williamson \& Tedeschi, unpublished) liver homogenates. NADPH was only slightly less effective than NADH with human liver (Feldstein, Williamson \& Tedeschi, unpublished) but considerably less effective than $\mathrm{NADH}$ with rat liver (Table 1). Again, we may consider the possibility of two distinct enzymes in liver, a NADH-linked and a NADPH-linked alcohol dehydrogenase, although a single enzyme which functions with both coenzymes should also be considered (Dalziel \& Dickinson, 1965).

In rat (Table 2) and human (Feldstein, Williamson \& Tedeschi, unpublished) brain homogenates, we have found that 5-HIAA formation was moderately stimulated by $\mathrm{NAD}^{+}$and to a lesser extent by NADP ${ }^{+}$. The quality of the $\mathrm{NAD}^{+}$may explain the difference between our results and those obtained by Eccleston et al. (1966), because enzymic activity was dependent on the source of the coenzyme (Table 3). The NAD ${ }^{+}$used in our studies was rated greater than $99 \%$ pure by the company and had maximal activity available. Also the presence of $\mathrm{NAD}^{+}$in commercial samples of $\mathrm{NADP}^{+}$may have played a part (Dalziel \& Dickinson, 1965) ; the NADP + used in our experiments was more than $99 \%$ pure and the company noted that the presence of $\mathrm{NAD}^{+}$could not be detected. Our results agreed with those of Deitrich and co-workers (Deitrich, 1966 ; Erwin \& Deitrich, 1966), who also found greater stimulation of 5-HIAA formation with NAD+ than with NADP+ in rat brain homogenates ; their isolated enzyme, in fact, showed no activity with $\mathrm{NADP}^{+}$. Hence, too, we may consider the possibility of two distinct enzymes in brain, a NAD+-linked and a NADP+-linked aldehyde dehydrogenase, although the possibility of a single enzyme which functions with both $\mathrm{NAD}^{+}$and NADP ${ }^{+}$cannot be excluded.

In agreement with the findings of Eccleston, Moir, Reading \& Ritchie (1966) we have found that NADPH moderately stimulated 5-hydroxytryptophol formation in rat brain homogenates (Table 2). We have also found that NADP+ added to rat brain homogenates fortified with NADPH caused a decrease in 5-hydroxytryptophol with a simultaneous increase in 5-HIAA formation (Table 4). These results may be explained in part by the presence of a NADPH-linked alcohol dehydrogenase and a NADP+-linked aldehyde dehydrogenase in the whole homogenate where NADP+ shifts aldehyde metabolism towards 5-HIAA formation and away from the NADPHinduced 5-hydroxytryptophol formation. These results also may be explained in part by a NADP+-induced inhibition of the NADPH-linked alcohol dehydrogenase resulting in decreased 5-hydroxytryptophol formation and increased 5-hydroxyindoleacetaldehyde and 5-HIAA formation. Whether the alcohol dehydrogenase is truly reversible as suggested (Eccleston, Moir, Reading \& Ritchie, 1966) can be determined only on the isolated and purified enzyme using both 5-hydroxytryptophol and 5-hydroxyindoleacetaldehyde as substrates. 
Eccleston, Moir, Reading \& Ritchie (1966) have also suggested that the NADPHlinked alcohol dehydrogenase which they found in rat brain is distinct from the $\mathrm{NADH}$-linked alcohol dehydrogenase found in rat liver. On the basis of the evidence now available (Tables 1 and 2), this conclusion may be correct. They also reported the presence of a NADPH-linked alcohol dehydrogenase in human brain and we have confirmed this for the human hypothalamus, thalamus, caudate nucleus and cerebral cortex (Feldstein, Williamson \& Tedeschi, unpublished). 5-Hydroxytryptophol formation was stimulated to a greater extent by NADPH than by NADH in rat (Feldstein \& Williamson, 1968 ; Otani, Farrell \& Creaven, 1968) and human (Feldstein, Williamson \& Tedeschi, unpublished) pineal homogenates.

We wish to acknowledge a grant from the U.S.P.H.S., N.I.M.H., National Center for the Prevention and Control of Alcoholism, MH 13540.

\section{REFERENCES}

Dalziel, K. \& Dickinson, F. M. (1965). The activity of liver alcohol dehydrogenase with nicotinamide-adenine dinucleotide phosphate as coenzyme. Biochem. J., 95, 311-320.

DeITRICH, R. A. (1966). Tissue and subcellular distribution of mammalian aldehyde-oxidizing capacity. Biochem. Pharmac., 15, 1911-1922.

Eccleston, D., MoIR, A. T. B., Reading, H. W. \& Ritchie, I. M. (1966). The formation of 5-hydroxytryptophol in brain in vitro. Br. J. Pharmac. Chemother., 28, 367-377.

ERwIN, V. G. \& DeITRICH, R. A. (1966). Brain aldehyde dehydrogenase: localization, purification, and properties. J. biol. Chem., 241, 3533-3539.

Feldstein, A. \& Williamson, O. (1968). Serotonin metabolism in pineal homogenates. Adv. Pharmac., 6, 91-95.

Feldstein, A. \& Wong, K. K. (1965a). Analysis of 5-HTP-C ${ }^{14}$ and its metabolites. Analyt. Biochem., 11, 467-472.

Feldstein, A. \& WoNG, K. K.-K. (1965b). Enzymatic conversion of serotonin to 5-hydroxytryptophol. Life Sci., 4, 183-191.

JouANY, J.-M. (1965). Action de quelques inhibiteurs metaboliques sur les taux de nicotinamideadenine dinucleotides dans le foie de rat. Annls Biol. clin., 23, 1097-1114.

Kveder, S., IsKrIC, S. \& Keglevic, D. (1962). 5-Hydroxytryptophol: a metabolite of 5-hydroxytryptamine in rats. Biochem. J., 85, 447-449.

Otani, T., Farrell, G. L. \& Creaven, P. J. (1968). Studies on the formation of 5-hydroxytryptophol in pineal. Fedn Proc., 27, 288.

PlaUt, G. W. E. \& AOGAICHI, T. (1967). The separation of DPN-linked and TPN-linked isocitrate dehydrogenase activities of mammalian liver. Biochem. biophys. Res. Commun., 28, 628-634.

SANADI, D. R. (1952). Enzymatic dephosphorylation of triphosphopyridine nucleotide. Archs Biochem. Biophys., 35, 268-277.

Stollar, V. \& KAPLAN, N. O. (1961). Incorporation of isotopically labelled precursors into the pyridine nucleotide coenzymes. J. biol. Chem., 236, 1863-1866.

Weissbach, H., Redfield, B. G. \& Udenfriend, S. (1957). Soluble monoamine oxidase; its properties and actions on serotonin. J. biol. Chem., 229, 953-963. 